\title{
Correspondence
}

We welcome letters to the Editor concerning articles which have recently been published. Such letters will be subject to the usual stages of selection and editing; where appropriate the authors of the original article will be offered the opportunity to reply.

Letters should normally be under 300 words in length, double-spaced throughout, signed by all authors and fully referenced. The edited version will be returned for approval before publication.

\section{Necrotising fasciitis of a limb}

Sir,

We read with interest the paper by Tang et $\mathrm{al}^{1}$ in the July 2001 issue entitled 'Necrotising fasciitis of a limb'. We wish to comment on the risk factors related to age, the site of disease and the antecedents.

Brandt, Corpron and $\mathrm{Wahl}^{2}$ found a mortality of $37 \%$ for patients over 50 years of age, $62 \%$ for those over 60 years and $100 \%$ for those over 70 years of age. Although some elderly patients survived in the series of Tang et al none had a proximal lesion of the limb. In the elderly, necrotising fasciitis of the groin or the hip appears to have a very bad outcome.

The site of the disease is indeed important for the prognosis. In the lower limb this is worse with proximal lesions, especially in the hip. Heitmann et $\mathrm{al}^{3,4}$ reported two deaths in two patients with lesions in the hip, one of whom was a 28 -year-old healthy woman who had had liposuction.

Frohlich and Schein ${ }^{5}$ and Roujeau et $\mathrm{al}^{6}$ reported that after surgery the mortality is between $50 \%$ and $70 \%$ instead of an overall mortality of between $20 \%$ and $40 \%$ if there was no previous operation. The mortality for patients with a colostomy is $50 \%{ }^{2}$

With regard to the diagnosis ultrasonography is a non-invasive, easy examination before surgical debridement and shows irregularity of the fascia, abnormal collections of fluid along the fascial plane and diffuse thickening of the fascia when compared with a control site. ${ }^{7,8}$

F. H. HOEFFEL, MD

J. C. HOEFFEL, MD

Nancy, France.

1. Tang WM, Ho PL, Fung KK, Yuen KY, Leong JCY. Necrotising fasciitis of a limb. J Bone Joint Surg [Br] 2001;83-B:709-14.

2. Brandt MM, Corpron CA, Wahl WL. Necrotizing soft tissue infections: a surgical disease. Am Surg 2000;66:967-70.

3. Heitmann C, Pelzer M, Bickert B, Menke H, Germann G. Surgical concepts and results in necrotizing fasciitis. Chirurg 2001;72:168-73.

4. Heitmann C, Czemak C, German G. Rapidly fatal necrotizing fasciitis after aesthetic liposuction. Aesthetic Plast Surg 2000;24:344-7.

5. Frohlich EP, Schein M. Necrotizing fasciitis arising from Bartholin's abscess: case report and review of the literature. Israel J Med Sci 1989;25:644-7.

6. Roujeau J, Saiag P, Brun-Buisson C, Touraine R. Microbial fasciitis. Rev Prat 1988;38:861-7.

C2001 British Editorial Society of Bone and Joint Surgery

0301-620X/02/513543 \$2.00

J Bone Joint Surg [Br] 2002;84-B:774-6.
7. Tsai CC, Lai CS, Yu ML, Chou CK, Lin SD. Early diagnosis of necrotizing fasciitis by utilization of ultrasonography. Kaohsiung $J$ Med Sci 1996;12:235-40.

8. Parenti GC, Marri C, Calandra G, Morisi C, Zabberoni W. Necrotizing fasciitis of soft tissues: role of diagnostic imaging and review. Radiol Med 2000;99:334-9.

\section{Authors' reply:}

Sir,

We thank the correspondents for their comments and the chance for us to reiterate a few important findings.

Our main objective was to review the outcome of necrotising fasciitis affecting a limb. We believe that our patients were different from those with necrotising fasciitis affecting other areas, e.g., a colostomy site, in terms of comorbidity, bacteriology, and clinical outcome. It is important to note that only $43 \%$ of patients in the series of Brandt, Corpron and Wahl ${ }^{1}$ had involvement of a limb.

We also realised the importance of the site of involvement in the prognosis. We regard the level of involvement in the limb on admission as the most important prognostic factor. In our 12 patients with proximal involvement, seven eventually died, whereas in the group with distal involvement, only one of 12 patients died (Fisher's exact test, $\mathrm{p}=0.027$ ). To the best of our knowledge, this correlation between the proximity of involvement and the mortality rate has not previously been reported, at least in the English literature.

Although a number of reports have claimed the benefit of using investigations like ultrasonography and MRI in the management of necrotising fasciitis, we consider these to be neither specific nor sensitive. They also inevitably delay the life-saving surgical debridement. We strongly believe that in an equivocal situation, an urgent diagnostic exploration should be carried out to expose the fascia. Those involved in managing this life-threatening infection should be aware that time is of the essence.

W. M. TANG, FRCS Ed

K. K. FUNG, FRCS Ed

J. C. Y. LEONG, FRCS Ed

P. L. HO, MRCP

K. Y. YUEN, MD

Department of Orthopaedic Surgery, The University of Hong Kong,

Hong Kong SAR, People's Republic of China.

1. Brandt MM, Corpron CA, Wahl WL. Necrotizing soft tissue infections: a surgical disease. Am Surg 2000;66:967-70.

\section{Conservative versus operative treatment for displaced ankle fractures in patients over 55 years of age}

Sir,

We read with interest the article by Makwana et $\mathrm{al}^{1}$ in the May 2001 issue entitled 'Conservative versus operative treatment for displaced ankle fractures in patients over 55 years of age'. We have some concerns about the conclusion that patients undergoing open reduction and internal fixation have significantly higher functional outcome scores than those treated non-operatively.

Of the original 43 patients included in the study seven were not formally assessed, six were unwilling to attend and one patient 
died leaving only 29 patients, a drop-out rate of $32 \%$. There is no mention of whether these patients were evenly distributed across the two arms of treatment. The authors then go on to discuss reviewing $19(86 \%)$ of the ORIF group and 12 (57\%) of the nonoperative group without any mention of what happened to the remaining patients or how this final number of 31 patients was achieved from an original 43. It is interesting that the final number of patients reviewed corresponds exactly to the number of anatomical reductions achieved. Since this number was significantly lower, $56 \%$ versus $86 \%$, in the non-operative group this would skew the results in favour of the ORIF group.

There is no mention of the comparative mean follow-up time between the ORIF and non-operative groups.

Of interest is that the first two Tables in the paper used 43 patients as their base number and the third 31. For Tables to be comparative the same number should be used in all. How is it possible to include an open fracture in this study since by standard treatment this fracture should have been treated by ORIF $^{2}$ and as such could not be randomised?

It is obvious from their data that there are advantages to using non-operative treatment for fractures of the ankle. There was a mean inpatient stay of 2.6 days against 6.7 days for the ORIF group $(\mathrm{p}=0.01)$. In the ORIF group three patients required further surgery, one is awaiting removal of the implant, two developed complex regional pain syndrome type-1, one developed a wound infection and one wound was left to heal by secondary intention. This is a total of eight complications in 19 patients, an incidence of $42 \%$. In the non-operative group one patient had a superficial wound infection and one symptomatic nonunion, a total of two out of 17 patients, giving a late and early complication rate of $12 \%$.

We believe that the above points call into question the statistical validity of the conclusion reached in the paper.

\section{A. A. FARAJ, FRCS Orth}

R. MONKHOUSE, FRCS

Bradford, UK.

1. Makwana N, Bhowal B, Harper W, Hui A. Conservative versus operative treatment for displaced ankle fractures in patients over 55 years of age: a prospective, randomised study. J Bone Joint Surg [Br] 2001;83-B:525-9.

2. Worlock P, Slack R, Harvey L, Mawhinney R. The prevention of infection in open fractures: an experimental study of the effect of fracture stability. Injury 1994;25:31-8.

\section{Author's reply:}

\section{Sir,}

We thank Messrs Faraj and Monkhouse for their interest in our paper. The seven patients who were not formally assessed at review included the six unable to attend and the one patient who died, giving a drop-out rate of $16 \%$ not $32 \%$. Of the six unable to attend five were in the closed treatment group and in one of these the fracture slipped. Of the 21 patients in the closed treatment group, 17 were reviewed at follow-up giving a follow-up rate of $81 \%$ which was comparable to that of the ORIF group. Out of the 17 reviewed 12 had no loss of reduction after closed treatment. The mean follow-up in both groups was 27 months with a range of 15 to 42 months in the closed treatment group and of 17 to 41 months in the ORIF group.

We agree with their comments that compound fractures should be excluded from the study. The one patient, however, who had a 'technically' compound fracture in the ORIF group had a small wound over the medial malleolus which did not communicate with the fracture. The wound was debrided and the fracture reduced according to our criteria before the patient was randomised into the study. The wound did not prevent treatment by closed methods and the patient was entered into the trial. The patient was randomised into the ORIF group.

With regard to their comment on complication rates the early complication rate in the ORIF group was $18 \%$ (two with complex regional pain syndrome, one with a superficial wound infection and one wound problem). In the closed treatment group the early complication rate was $42 \%$ if loss of reduction was included (eight with loss of reduction and one with a wound problem). It should be noted that all the early complications in the ORIF group had resolved by review. The rate of late complications in the ORIF group was $26 \%$ if removal of metalwork was considered to be a complication (three had removal of metalwork, one is awaiting removal and two had scar tenderness). In the closed treatment group the rate was $23 \%$ with two cases of malunion and two of nonunion. Although all of these patients did not have symptoms the long-term consequences on the ankle are not known. We agree that ORIF is not without complications, but our study shows that the functional results are better in this group. We feel that the conclusions reached in our paper are valid.

N. K. MAKWANA, FRCS

Wrexham, UK

\section{The translated two-part fracture of the proximal humerus}

Sir, I read with interest the article by C. M. Court-Brown et al ${ }^{1}$ entitled 'The translated two-part fracture of the proximal humerus' in the August 2001 issue.

I disagree with some of the methods used in the study and the conclusions reached by the authors. There was no randomisation of the types of treatment and the admitting consultant made the choice. This immediately brings in selection bias. It has to be assumed that the more elderly and infirm patient will be less likely to be operated on in such a situation and the authors report that the patients in the 80-to-99-year age group were not satisfied with the treatment which they received. Was this mainly conservative treatment? I feel that the authors have lost the chance to examine the most important aspect in this age group, namely, whether it is better to stabilise the fracture by means of an intramedullary nailing technique rather than an extramedullary method such as plating, in order to mobilise the shoulder early, when compared with conservative measures.

Of the 126 patients, final conclusions seem to have been drawn from just 49 (38\%) whose displacement was more than 66\%. I agree that the more displaced fractures are more likely to be treated by a surgical method in most hospitals, but here for some reason most of these $(31,63 \%)$ seem to have been treated nonoperatively (Table III). Again it has to be assumed that this decision was related to age because 54 fell into the age group between 70 and 99 years. Table III is still more confusing since the breakdown by age shows only 75 patients rather than the expected 126.

The authors report that $64.5 \%$ of patients had good or excellent results in their study and also suggest that the return to activities of daily living was not satisfactory in the elderly. Did the elderly fare worse after internal fixation or conservative treatment? Table III shows that with the exception of personal hygiene, the operated group with a mean age of 73 years and displacement of more than $66 \%$ did much better than the non-operated group with an average of 78 years in terms of return to activities such as shopping, dressing and housework.

The operative treatment quoted is flexible intramedullary nailing and tension-band wiring but we are not told whether this was closed, locked nailing or Rush nailing with open tension-band 
wiring or some other method. These would be expected to affect the soft tissues around the shoulder differently by the very nature of the procedure. On the basis that preservation of the soft-tissue envelope around the fracture would give it the best chance of healing, a closed nailing procedure would be expected to fare better.

K. R. RAJESH, MS (Orth), Dip NB (Orth), FRCS, FRCS (Trauma \& Orth)

Hope Hospital

Manchester, UK.

1. Court-Brown CM, Garg A, McQueen MM. The translated two-part fracture of the proximal humerus: epidemiology and outcome in the older patient. J Bone Joint Surg [Br] 2001;83-B:799-804.

2. Hintermann B, Trouillier HH, Schafer D. Rigid internal fixation of the fractures of the proximal humerus in older patients. J Bone Joint Surg [Br] 2000;82-B:1107-12.

3. Robinson CM, Christie J. The two-part proximal humeral fracture: a review of operative treatment using two techniques. Injury $1993 ; 24: 123-5$.

\section{Author's reply:}

\section{Sir,}

We thank Mr Rajesh for drawing our attention to a discrepancy in Table III of our paper. We apologise for publishing the incorrect numbers of patients in the different age groups. However, the outcome scores are accurate and the patient numbers are less important. We agree that randomised control trials are ideal, but until this study was undertaken there was no debate in the literature regarding the management of these fractures. Judging by Mr Rajesh's letter there now is and randomised trials should follow.

There may have been a selection bias but Table III indicates that the operative and non-operative groups were virtually identical in age, fracture displacement and prefracture activity level which are the most important factors. The decision to operate was not based on age or infirmity.

Mr Rajesh is wrong in saying that one is left to guess the outcome of treatment in the elderly. Table III is quite clear and indicates no advantage to surgery. He is also wrong in stating that the operated group returned to normal activity in a shorter time. We specifically stated in the paper that there was no significant difference between the groups at one year. We also believe that $\mathrm{Mr}$ Rajesh is somewhat disingenuous in his remarks about surgical techniques. Our paper is quite clear that Rush pins and tension banding were used in 17 of the 18 patients who were treated operatively. The remaining patient received a plate. There have been very few studies on operative management of two-part fractures of the surgical neck, but a retrospective study published by Robinson and Christie in $1995^{1}$ examining the use of Rush pins and tension banding showed virtually identical results to those achieved by us using non-operative management. They had an average Neer score of 84 and $69 \%$ of patients had good or excellent results. Being retrospective their follow-up times varied. The implication that locked nailing will give better results is entirely unproven and we doubt that it will, but until it is proven to be superior to non-operative management we suggest that $\mathrm{Mr}$ Rajesh uses non-operative treatment for elderly patients with twopart fractures of the proximal humerus.

C. M. COURT-BROWN, MD, FRCS Ed (Orth)

The Royal Infirmary of Edinburgh

Edinburgh, UK.

1. Robinson CM, Christie J. The two-part proximal humeral fracture: a review of operative treatment using two techniques. Injury 1995;24:123-5.

\section{The floating shoulder: a multicentre study}

Sir,

With reference to the article in the August 2001 issue entitled 'The floating shoulder' ${ }^{, 1}$ the authors have shown that adverse results are to be expected if there is caudal dislocation of the glenoid. Unfortunately, it does not define the criteria for the absence or presence of caudal dislocation so that the reader is unable to determine whether he or she should consider operative treatment. Indeed, the orientation of the lateral margin of the scapula with respect to the glenoid fossa is comparable in Figures 1 and 2 and the abduction of the arm in Figure 2 may be the most apparent difference from Figure 1. I think that it would be helpful for the reader if the authors could clarify which is the most important outcome parameter of their study.

\section{GERBER, MD \\ University of Zürich \\ Switzerland.}

1. van Noort A, te Slaa RL, Marti RK, Werken $\mathbf{C}$ van der. The floating shoulder shoulder: a multicentre study. J Bone Joint Surg [Br] 2001;83-B:795-8.

\section{Authors' reply:}

\section{Sir,}

We thank Professor Gerber for his interest in our article and his comment. The rotational malalignment of the glenoid was assessed by measuring the inclination of the glenoid on an anteroposterior radiograph in the scapular plane. This is the angle formed by the two perpendicular lines drawn on the line connecting the most cranial with the most caudal point of the glenoid cavity and the tangent along the medial border of the scapula (Fig. 1).

The inclination of the glenoid is variable as was recently reaffirmed in an anatomical study by Churchill et al. ${ }^{1}$ The mean glenoid inclination for their study group of 344 scapular bones was $4^{\circ}$ of superior angulation, ranging from $7^{\circ}$ of inferior angulation to $16^{\circ}$ of superior angulation.

We arbitrarily defined the glenoid as 'caudally dislocated' if the inferior angulation was $20^{\circ}$ or more.

\section{A. VAN NOORT, MD}

R. L. te SLAA, MD

R. K. MARTI, MD, PhD

C. VAN DER WERKEN, MD, PhD

Reinier de Graaf Hospital

Delft, The Netherlands.

1. Churchill RS, Brems JJ, Kotschi H. Glenoid size, inclination and version: an anatomic study. J Shoulder Elbow Surg 2001;10:327-32.

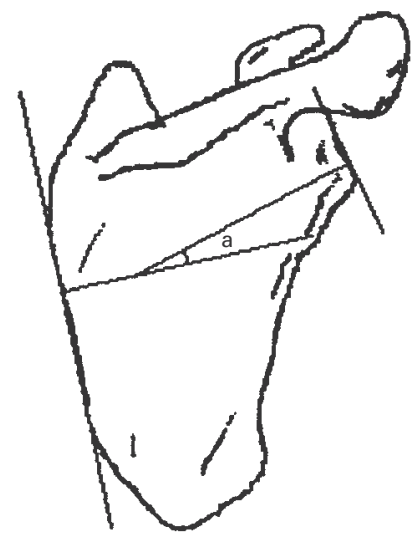

Fig. 1

Diagram showing the inclination angle (a). 